\title{
The Impact of Integrated Narrative Therapy and Imago Therapy on Depression among the Mournful Women
}

\author{
Bafandegan Vahid \\ Department clinical psychology, Neyshabur University, Iran \\ Correspondence should be addressed to Bafandegan Vahid, vahid_bafandegan@yahoo.com
}

Received: December 17, 2020; Accepted: December 24, 2020; Published Date: January 22, 2020

\begin{abstract}
$\underline{\text { ABSTRACT }}$
\section{BACKGROUND \& OBJECTIVES}

The frequent Comorbidity of depressive disorder and other disorder is well- documented. The impact of integrated narrative therapy and imago therapy is designed as a treatment to influence emotional problem. The aim of the present study was to investigate the effect of integrated narrative therapy and imago therapy on depression women among the mournful women in Mashhad.
\end{abstract}

\section{METHODS AND MATERIALS}

Of the 75 women the sample included 24 participants who were assigned by random sampling in experimental $(\mathrm{N}=12)$ and control group ( $\mathrm{N}=12)$. Women were completed the Beck Depression short Inventory (BDI-13) in the pre-test, post-test. Data were analysed with the SPSS 16 and presented with covariance (ANCOVA) test Alpha level of less than .05 was considered significant $(\mathrm{p}<0.05)$.

\section{FINDINGS}

Analysis of ANCOVA showed that there are significant differences between the experimental and control group based on the depression $(\mathrm{f}=184.8, \mathrm{p}<0.001)$ in the post-test stage.

\section{CONCLUSION AND RESULTS}

Suggest that impact of integrated narrative therapy and imago therapy can be an effective treatment.

\section{KEYWORDS}

Narrative therapy; Imagotherapy; Depression; Women

\section{INTRODUCTION}

Some interventions target thought processes. They can take an important step in developing new skills and

Citation: Bafandegan, Vahid, The Impact of Integrated Narrative Therapy and Imago therapy on Depression among the Mournful Women. Psychiatry 1(1): 13-17. abilities. Narrative therapy and imago therapy approaches are examples of them. Narrative therapy is the process of helping people so that people can overcome their 
problems by engaging in therapeutic conversations. These conversations include problem solving, extracting consequences, highlighting new maps, and connecting them to the past [1]. In narrative therapy, it is believed that people give meaning to their lives and experiences through narratives and the existence of negative narratives leads to problems and the source of the problem is a story full of failure, despair and sadness [2]. Therefore, the main purpose of narrative therapy is to help clients to revise and correct internal stories. This process enables clients to anticipate and control themselves [3]. Research has shown that people who were able to cope with the narratives and stories of past lives. They can more easily cope with current events. Imago therapy is one of the most exciting and interesting educational methods. Imago therapy is a tool for conscious communication which consciously heals the injuries of the past. Based on a theoretical principle, it is believed that the process of image therapy is included that people can understand their psychological damage and they try to learn new skills and interpret painful behaviours [4]. The study included all women who had lost their husbands in the war. These people are known as the wives of martyrs [5]. in the study of remarriage of martyrs 'wives concludes that due to religious factors, only $24 \%$ of martyrs' wives have remarried. Research has shown that the main reason for women not marrying is religious factors and loyalty to the martyr. For this reason, they sometimes have relations outside the cultural norm and secret relationship. So they experience a lot of communication problems. One of the reasons why research is so important: Working with the wives of the martyrs and their families. Normally, working with the families of martyrs is prohibited and this has made the society indifferent to them.

\section{Intervention Package}

Session1: Expressing the purpose of forming a group and the importance of the subject, understanding the concept of what stories in a person's life and childhood lead to anxiety

Session 2: Review childhood memories and discover the structure of Imago, review the history of intimate relationships and

Discover failures.

Session 3: Preparing to tell a life story. Check homework

Session 4: Determining positive factors in past stories with people and the impact of past reactions on people's current depression. Check homework

Session 5: Examine priorities, aspirations, goals, and important people. Check homework

Session 6: Communication analysis in narrative. Check homework

Session 7: Final edition of the new narrative. Check homework

Session 8: Familiarity with the needs and harms of others based on new narrative and discovery of new metaphors. Check homework

Session 9: New communication skills and intimacy. Check homework

Session 10: The concept of excitement-Types of excitement: pleasure; Anxiety; Anger, rage, shame-

Resolve past sufferings and heal emotional wounds. Check homework

Session 11: Behavioural skills training and familiarity with techniques for creating happiness and emotional connection

Session 12: Feedback from group members about the package and activities of the course to explore internal change. Playing questionnaires. [6,7]

\section{METHODOLOGY}

This research is an experimental search with pre-test and post-test with the control group. Statistical population of the study consisted of all patients' depression in special centres of Women who lost their husbands in the war in the city of Mashhad, which sample selected cluster sampling method. As such, it was selected from the seven regions of Mashhad, finally, three counselling centres 
were selected from all of the areas. Based on the clinical interview was DSM -IV The number of 24 people whose depression scores were in the 12-15 (moderate depression) range selected. During this treatment, two groups of 12 individuals, including the experiment group and the control group that was random. Age between 2055 years, lack of diagnosis or other problems affecting the participant's illness. Psychiatric drugs (including benzodiazepines, any type of antidepressant) for more than two weeks prior to the onset of therapeutic intervention. Patients with the above conditions entered into the study with a consent form. Data were analysed with the SPSS 16 and presented with covariance (ANCOVA) test. The treatment took place in a group the 12-session. Due to the specific conditions of the political, the treatment was done in a short time. The program included strategies and Therapeutic techniques with Impact of integrated narrative therapy and imago therapy. The literature research has been based on research $[6,8]$.

\section{INSTRUMENT}

Beck's Depression Inventory 2 (BDI-II). Beck's Depression Inventory is a 21 -item inventory and is one of the most important self-report instruments to measure depression. The inventory has good validity and reliability. Validity and reliability of the inventory in Iran are measured in a study. Cronbach alpha of the inventory is equal to 0.91 and reliability is reported to 0.96 using retest method [9].

\section{FINDING}

According to the findings of this study, there is no significant difference between the experimental and control group in terms of age $(\mathrm{P}=0.26)$ and mourn $(\mathrm{P}=0.42)$. In other words, groups are peers in terms of the variables studied. In analyzing the results, supported by to same of the regression line $(\mathrm{p}=0.65 \& \mathrm{~F}=0.207)$ and Levine test $(\mathrm{p}=0.13 \& \mathrm{~F}=2.43)$. Therefore, it is allowed to perform ANCOVA. In this study, a pre-test score of depression was known as the synchronous variable and its effect on the present test scores was controlled using the covariance analysis (Table 1).

\begin{tabular}{|c|c|c|c|c|c|}
\hline \multicolumn{3}{|c|}{ Post-test } & \multicolumn{2}{c|}{ Group Pre-test } \\
\hline SD & M & SD & M & \multicolumn{2}{|c|}{ Number } \\
\hline $1 / 6$ & & & & \multicolumn{2}{|c|}{ Excremental } \\
\hline 1 & $17 / 33$ & $2 / 24$ & $23 / 83$ & 12 & \\
\hline $1 / 4$ & & & & & \\
\hline 0 & $24 / 16$ & $1 / 89$ & $25 / 83$ & 12 & Control \\
\hline
\end{tabular}

Table 1: Descriptive indicate related to depression.

Findings (Table 2) indicates that the difference observed between the participants 'depression scores that significant in terms of group membership in the post-test. Thus, the treatment of integrated narrative therapy and imago therapy group in the recovery of the depression of women has been affected. High statistical potential 0.80 indicates the adequacy of the sample and statistical accuracy.

\begin{tabular}{|l|l|l|l|l|l|l|}
\hline ETA & P & F & MM & Df & SS & \\
\hline 0.65 & 0.000 & 39.61 & 32.89 & 1 & 32.89 & Pre-test \\
\hline 0.89 & 0.000 & 184.82 & 153.47 & 1 & 153.47 & Group \\
\hline & & & 0.83 & 21 & $17 / 43$ & Error \\
\hline
\end{tabular}

Table 2: Summary depression scores.

\section{DISCUSSION}

The present study is in line with the research of [6]. In explaining this result, we can say: The main theme in narrative therapy; Paying attention to dysfunctional beliefs and changing them; Externalize and neutralize them; Looking at the problem from the outside and paying attention to its various dimensions; Finally, creating a different interpretation and different roles to create the narrative of a person's life story [7]. The narrative therapy process involves telling the story again. It helps people to understand their relationship with their partner. In fact, it is important to discover people's stories. The primary emphasis of narrative therapy is on the interpretation that people give to the events and happenings of their lives. Understanding life events can limit or expand a person. Narratives help clients gain broader interpretations. Considering these cases, the effectiveness of the narrative therapy approach on 
improving depression can be justified [8]. Imago therapy deals with the subject with a new structure and he does not think of it as a second issue. In this method, the formation of a new relationship and its process are discussed and the therapist and the client go in search of identify the client partner [10]. The structure of imago therapy deals with the denied aspects of a person's personality and by presenting a real image of love, it reconstructs people's imaginary image [11]. Obtained, it can be concluded that the treatment of integrated narrative therapy and imago therapy can affect the treatment of depression and reduce it. The limitation of this study is to be specific to sample and not - follow - up that the need for caution in generalizing. It is suggested that research in other psychotherapy, clinical centre.

\section{REFERENCES}

1. Carr A (1998) Michael White's narrative therapy. Contemporary Family Therapy 20(4): 485-503.

2. Looyeh MY, Kamali K, Ghasemi, A et al. (2014) Treating social phobia in children through group narrative therapy. The arts in Psychotherapy 41(1): 16-20.

3. Polkinghorne DE (2014) Narrative therapy and postmodernism. In Angus, L. E \& McLeod, J. (Eds.).The handbook of Narrative and psychotherapy. Sage publications India Pvt. Ltd., India.

4. Hendrix H (2006) How to keep your relationship shape: An introduction to Imago.

5. Ahmadi K (2004) A comparative study of remarriage effects on psychological hygiene of martyr's spouses and widows. Clinical Psychology and Personality 2(2): 35-45.

6. Mohamadian Z, Goudarzi K, Sadeghi M (2019) The impact of integrated narrative therapy and imagotherapy on attitudes to marriage in marriage volunteers. Journal of Psychologicalscience 18(81): 1081-1088.

7. Bichescu D, Neuner F, Schauer M, et al. (2007) Narrative exposure therapy for political imprisonment-related chronic posttraumatic stress disorder and depression. Behaviour Research and Therapy 45(9): 2212-2220.

8. Madigan S (2011) Narrative therapy. American Psychological Association.

9. Rajabi GH (2007) Properties psychometric of the beck depression inventory-short form (BDI-13). Developmental Psychology (4): 291-298.

10. Hendrix H, Hannah M T (2013) Case studies in couples therapy: Theory-Based Approaches. Imago relationship therapy, 205.

11. Zielinski JJ (1999) Discovering imago relationship therapy. Psychotherapy: Theory, Research, Practice, Training 36(1): 91.

12. Hendrix H, Hannah MT (2013) Imago relationship therapy. Case Studies in Couples Therapy: Theory-Based Approaches, 205.

13. Sharafi MG, Zadeh FA (2017) Evaluation of effectiveness imago relationship therapy on fear of negative evaluation in betrayed couples divorce in Shiraz. International Journal of Psychology and Behavioral Sciences 7(4): 103-106.

14. Payne M (2006) Narrative therapy. Sage, India. 